Review

\title{
Scar tissue to lung cancer; pathways and treatment
}

\author{
Konstantinos Sapalidis ${ }^{1}$, Chrysanthi Sardeli², Efstathios Pavlidis ${ }^{1}$, Georgios Koimtzis ${ }^{1}$, Charilaos \\ Koulouris ${ }^{1}$, Nikolaos Michalopoulos ${ }^{1}$, Stylianos Mantalovas ${ }^{1}$, Theodora Tsiouda ${ }^{1}$, Ioannis Passos ${ }^{1}$, \\ Christoforos Kosmidis' ${ }^{1}$, Dimitrios Giannakidis' ${ }^{1}$, Valeriu Surlin ${ }^{1}$, Athanasios Katsaounis ${ }^{1}$, Vyron \\ Alexandrou ${ }^{1}$, Aikaterini Amaniti ${ }^{3}$, Paul Zarogoulidiss, ${ }^{1}$, Haidong Huang4, Qiang Li ${ }^{4}$, Stelian Mogoanta ${ }^{5}$, \\ Isaac Kesisoglou ${ }^{1}$ \\ 1. Third Department of Surgery, "AHEPA" University Hospital, Aristotle University of Thessaloniki, Medical School, Thessaloniki, Greece; \\ 2. Department of Pharmacology \& Clinical Pharmacology, School of Medicine, Faculty of Health Sciences, Aristotle University of Thessaloniki, Thessaloniki, \\ Greece; \\ 3. Anaisthisiology Department, "AHEPA" University Hospital, Aristotle University of Thessaloniki, Medical School, Thessaloniki, Greece. \\ 4. The Diagnostic and Therapeutic Center of Respiratory Diseases, Shanghai East Hospital, Tongji University, Shanghai, China. \\ 5. Department of Surgery, Faculty of Dentistry, University of Medicine and Pharmacy of Craiova, Craiova, Romania.
}

$\square$ Corresponding author: Paul Zarogoulidis, MD, PhD, Department of Pharmacology \& Clinical Pharmacology, School of Medicine, Faculty of Health Sciences, Aristotle University of Thessaloniki, Thessaloniki, Greece. Mobile: 00306977271974; Email: pzarog@hotmail.com Or Konstantinos Sapalidis, MD, PhD. 3rd Department of Surgery, "AHEPA" University Hospital, Aristotle University of Thessaloniki, Medical School, Thessaloniki, Greece. email: sapalidiskonstantinos@gmail.com

( ) Ivyspring International Publisher. This is an open access article distributed under the terms of the Creative Commons Attribution (CC BY-NC) license (https:// creativecommons.org/licenses/by-nc/4.0/). See http://ivyspring.com/terms for full terms and conditions.

Received: 2018.09.30; Accepted: 2018.12.15; Published: 2019.01.30

\begin{abstract}
Lung cancer still remains diagnosed at a late stage although we have novel diagnostic techniques at our disposal. However; for metastatic disease we have novel therapies based on pharmacogenomics. Tumor heterogenity provides us different treatments. There are several reasons for carcinogenesis; fibrosis and scar tissue provides an environment that induces malignancy. In the current review we will try and elucidate the pathways involved from scar tissue to carcinogenesis.
\end{abstract}

Key words: lung cancer, scar tissue, interstitial disease, fibrosis, pathways

\section{Introduction}

Lung cancer still remains diagnosed late although we have novel diagnostic techniques such as the electromagnetic navigation, radial endobronchial ultrasound and convex probe endobronchial ultrasound (EBUS).[1-3] However; for metastatic disease in non-small cell lung cancer (NSCLC) we have novel targeted treatments based on the epidermal growth factor (EGFR), anaplastic lymphoma kinase (ALK), proto oncogene (BRAF) and proto-oncogene tyrosine-protein kinase (ROS1) expression with tyrosine kinase inhibitors (TKIs). $[4,5]$ We use next-generation sequencing (NGS) for the investigation of these genes. Another technique is the cobas $^{\circledR}$. The cobas ${ }^{\circledR}$ EGFR Mutation Test v2 is a real-time PCR test that identifies 42 mutations in exons 18, 19, 20 and 21 of the epidermal growth factor receptor (EGFR) gene, including the T790M resistant mutation. It is designed to enable testing of both tissue and plasma specimens with a single kit, and allows labs to run tissue and plasma on the same plate simultaneously. For optimized workflow results, Roche has developed a cell-free DNA (cfDNA) sample preparation kit to optimize extraction of DNA from plasma.[6, 7] Proto oncogene BRAF and proto oncogene KRAS can be also investigated with the cobas $^{\circledR}$ technique.[8] Unfortunately liquid biopsy has its limitations as it is only $60 \%$ efficient with some studies going to $70 \%$ for investigation of EGFR and T790M.[9, 10] Liquid biopsy can be performed easily by acquiring blood sample of 10cc and it is usually considered for patients that cannot undergo biopsy due to performance status or even lack of diagnostic equipment. Liquid biopsy is considered to investigate the mutation burden that circulates through the body. 
On the other hand tissue is always considered the best material in order to investigate gene expressions, however; the site of the biopsy has to be chosen carefully.[11] It has been observed that different lesions have different gene expressions, the main site could have EGFR positive expression, while metastasis not. Moreover; metastasis in different sites of the body might be a different cancer as it has been observed in previous case reports.[12, 13] Usually adenocarcinoma tends to transform to small cell lung cancer either due to tyrosine kinase inhibitors or on its own due to a cascade of inflammatory proteins that are secreted from the tumor.[14-16] Therefore upon follow up careful evaluation should be made of the main lesion and metastasis and re-biopsy should be made to the site which is not responding according to the primary lesion. Tyrosine kinase inhibitors (TKIs) currently on the market are; gefitinib, erlotinib and afatinib. The main side effects are skin rash, diarrhea and in some cases pneumonitis.[17] The first two can be handled with drugs or dose reduction, however; pneumonitis is a more severe side effect and in some situations the patient has to stop the treatment and the same time corticosteroids have to be administered.[17] Unfortunately in several patients disease progression due to tki resistance and therefore the mutation $T 790 \mathrm{M}$ is investigated and if found then a second generation tki is administered osimertinib.[18] The EGFR and T790M mutation can be also detected from different fluids using cell blocks. $[19,20]$ Currently we are investigating whether osimertinib could be administered as first line treatment to EGFR mutant patients due to the FLAURA trial.[21, 22] Regarding ALK mutation crizotinib is administered as first line treatment.[23] The ALK mutation can be only detected in tissue samples.[24] Again if resistance is observed then ceritinib or alectinib and be administered without investigation of any additional gene expression.[25, 26] The usual side effects of these pills are vomiting, diarrhea, constipation, swelling in your hands, feet, ankles, face, and eyelids. Moreover; in the united states another tki brigatinib might be soon a treatment options after first line treatment progression.[27] Proto-oncogene tyrosine-protein kinase (ROS1) is detected in tissue samples and crizotinib is administered as first line treatment. [28] Ceritinib has been also investigated in ROS1 patients after crizotinib resistance.[29] Regarding proto oncogene (BRAF) dabrafenib/trametinib are administered as first line treatment.[30] Most common side effects are diarrhea, skin toxicities, pyrexia and arthralgia. BRAF can only be detected in tissue sample.[31] Currently we are investigating a three drug administration for these patients as first line treatment.[32]
Chemotherapy and immunotherapy remains the treatment choice as second line treatment in these patients.

Immunotherapy ( $\mathrm{IO}$ ) has also been introduced as a novel treatment in the past two years and it is based on the programmed death-ligand 1 (PD-L1) expression. In specific pembrolizumab can be administered as first line treatment if PD-L1 $\geq 50 \%$ and as second line treatment if PD-L1 $\geq 1 \%$. In the case of nivolumab it can be administered as second line treatment indifferent of the PD-L1 expression.[33] Regarding small cell lung cancer (SCLC) chemotherapy and recently immunotherapy as second line treatment are considered the best therapeutic approach.[34] It has been observed that during the treatment of lung cancer interstitial pneumonitis might occur. Often this adverse effect is fatal. Moreover; for many lung cancer with idiopathic pulmonary fibrosis radiotherapy is contraindicated and the applicability of chemotherapy regimens is also limited.

In particular, gemcitabine, irinotecan, and amrubicin are, respectively, contraindicated in these patients. Whenever possible surgery is selected for resectable tumors in the treatment of such cancer, although strict criteria are used even though surgery is also a known risk factor for AE. It has been observed that the incidence of postoperative adverse events of interstitial pneumonitis varies among patients by their demographics and interstitial pneumonitis subtypes. In the study by Goto T. et. al. [35] a univariate analysis revealed significant correlations with adverse events for the following factors: gender, preoperative history of steroid use, preoperative C-RP (C-reactive protein), preoperative adverse events of interstitial pneumonitis, LDH (lactate dehydrogenase), KL-6 (Krebs von den Lungen-6), \%VC (vital capacity), $\mathrm{FEV}_{1}$ (forced expiratory volume in $1 \mathrm{sec}$ ), $\mathrm{FEV}_{1} \%$, operative time, blood loss, DLCO (carbon monoxide diffusing capacity of the lung), imaging findings of interstitial pneumonitis, and the surgical procedure used (VATS vide-oassisted vs open surgery). A subsequent multivariate analysis of these factors identified the following as significant respective risk factors for adverse eveant: male gender, KL-6 > $1000 \mathrm{U} / \mathrm{mL}$, preoperative steroid use, \%vital capacity $<80 \%$, UIP pattern, history of adverse events, segmentectomy vs a more extensive surgical procedure.

In the current review we will focus on those patients who developed lung cancer based on scar tissue from fibrosis as this has been previously observed.[36] 


\section{Molecular pathways}

There are epigenetic and genetic alterations, abnormal expression of microRNAs (miRNAs), cellular and molecular aberrances such as an altered response to regulatory signals, delayed apoptosis or reduced cell-to-cell communication, along with the activation of specific signaling transduction pathways, all these characterize the pathogenesis of both IPF and LC.[37, 38] In idiopathic pulmonary fibrosis lung tissue, we have previously identified that increased tissue stiffness is a function of dysregulated post-translational collagen cross-linking rather than any collagen concentration increase whilst at the nanometre-scale collagen fibrils are structurally and functionally abnormal with increased stiffness, reduced swelling ratio, and reduced diameter.[39] Inflammatory monocytes (IMs) exist are a reason for the development of scar tissue and they are found in pathological tissue specimens. Squamous cell lung carcinomas are characterized by a dense infiltration of inflammatory monocytes (IMs) and poor survival. Chemokine (C-C motif) ligand 2 (CCL-2) mediate recruitment of IMs which is necessary and sufficient for squamus cell lung cancer metastasis. It has been observed that pharmacologic inhibition of IM recruitment had substantial anti-metastatic effects. Moreover; IMs highly express Factor XIIIA, which promote fibrin cross-linking to create a scaffold for squamus cell lung cancer cell invasion and metastases.[40] Insulin like growth factor -1 (IGF-1) signaling deficiency is known to result in alveolar hyperplasia in humans and disrupted lung architecture in animal models. The components of IGF-1 signaling pathways are potentiated as biomarkers as they are dysregulated locally or systemically in lung diseases, whereas data may be inconsistent or even paradoxical among different studies.[41] Immunological and genetic analyses have affirmed the expression of IGF-1 signaling components in cells from the normal lung tissue, lung parenchymal cells, including airway cells, smooth muscle cells, lung fibroblasts, and alveolar macrophages.[42] Abnormal IGF-1 expression is associated with lung cancer and fibrosis.[43] Abnormal IGF-1/IGF-1R signaling has been extensively studied in lung cancer and it has been observed to mediate oncogenesis, progression, metastasis, resistance to chemotherapy, and tyrosine kinase inhibitors (TKIs).[44] Therefore it has been observed that patients receiving TKIs some patients develop pneumonitis.[45] Moreover; IGF-1 is implicated in the epithelial-mesenchymal transition (EMT) induction and cancer stem cell (CSC) maintenance, however; no clear conclusions can be drawn since the patients with lung cancer were selected randomly in previously published studies.[46] There are evidence that ZEB1-mediated EMT in human alveolar epithelial type II (ATII) cells contributes to the development of lung fibrosis by paracrine signaling to underlying fibroblasts.[47] In human fibrotic lung tissue, it was observed that ZEB1-mediated paracrine signaling has the potential to contribute to early fibrotic changes in the lung interstitium. Possibly targeting this pathway ZEB1 regulatory axis may be a future treatment strategy of pulmonary fibrosis.[47] Regulating this pathway we might have a treatment for lung fibrosis and reduce lung cancer prevalence.

It has been observed that with aging the following genes (TERT, DSP and FAM13A) lose their normal function and their deregulation is associated with the development or exacerbation of chronic obstructive pulmonary disease (COPD), idiopathic pulmonary fibrosis (IPF) and lung cancer.[48] The enzyme telomerase reverse transcriptase (TERT) is essential for telomere maintenance. In replicating cells, maintenance of telomere length is important for the preservation of vital genetic information and prevention of genomic instability. TERT SNP rs $2736100 \mathrm{C}$ allele has been found to be positively associated with multiple cancerous diseases, on the other hand the A allele is positively associated with predisposition to non-cancerous (degenerative) diseases. Its influence on telomere length, illustrates that optimal telomere maintenance reduces the risk for cancer or for non-cancerous diseases. This underlines the caution that should be taken when developing therapies that influence telomere length.[49] $\beta$-catenin/CTNNB1 is an intracellular scaffold protein that interacts with adhesion molecules (E-cadherin/CD H1, N-cadherin/CD H2, VE-cadherin/CD H5 and a-catenins), transmembrane-type mucins (MUC1/CD 227 and MUC16/CA125), signaling regulators (APC, AXIN1, AXIN2 and NHERF1/EBP50) and epigenetic or transcriptional regulators (BCL9, BCL9L, CREBBP/ CBP, EP300/p300, FOXM1, MED12, SMARCA4/ BRG1 and TCF/LEF). $\beta$-catenin/CTNNB1 dysfunction has been associated with fibrosis and lung cancer, therefore it has been proposed as treatment target.[50] The phosphoinositide 3-kinase $(\mathrm{PI} 3 \mathrm{~K}) /$ protein kinase $\mathrm{B}(\mathrm{AKT}) /$ mammalian target of rapamycin (mTOR)-dependent pathway is one of the most integral pathways linked to cell metabolism, proliferation, differentiation, and survival. The dysregulation of this pathway is observed in idiopathic pulmonary fibrosis and lung cancer. Therefore mTOR inhibitors could be used for the regulation of the pathway.[51] Plasmacytoid DCs (pDCs) are unaffected or are reduced systemically, 
however; they tend to increase in the affected organs (lungs/skin/bronchoalveolar lavage). Plasmacytoid DCs are observed in high concentrations in the lungs of patients with systemic sclerosis and have been correlated with the severity of lung disease along with the frequency of CD4+ and IL-4+ T cells in the lung. It has been observed that treatment with imatinib reduces and/or prevents deterioration of skin and lung fibrosis and profoundly reduced pDCs in lungs but not in peripheral blood of patients with systemic sclerosis.[52] Transforming growth factor (TGF)- $\beta$ regulates cell growth arrest, invasion, motility, apoptosis, cell differentiation, angiogenesis, extracellular matrix production, tissue fibrosis, and immune function. Although tumor-suppressive roles of TGF- $\beta$ have been extensively studied and the critical roles of TGF- $\beta$ as a pro-tumorigenic factor in various types of cancer remain to be elucidated. TGF- $\beta$ plays a pivotal role in the differentiation and function of regulatory T cells (Tregs).[53] Therefore by targeting this pathway we could have a novel treatment.

Several oncomirs, microRNAs associated with malignancy, are also linked with IPF. miR-29a and miR-185 downregulation is probably involved both in carcinogenesis and fibrogenesis. Common targets of miR-29a and miR-185 such as DNA methyltransferase (DNMT)1, DNMT3b, COL1A1, AKT1 and AKT2 have been investigated. Similar levels of miR-29a and miR-185 were detected in interstitial pulmonary fibrosis (IPF) and lung cancer (LC) while their common targets AKT1 and DNMT3b were not found to differ. Possibly there are pathogenetic similarities at the level of key epigenetic regulators. On the other hand COL1A1 mRNA levels were increased in interstitial pulmonary fibrosis suggesting a disease-specific mRNA signature. DNMT1 was downregulated in the lung cancer group and its expression was further reduced in the presence of increasing malignant burden as it was implied by the endobronchial findings.[54] The expression levels of FGF2 mRNA and protein in the non-small cell LC tissues were significantly higher than those in the adjacent normal tissues $(\mathrm{P}<0.001)$. The expression level of FGF2 protein in lavage fluid of patients with IPF was higher than that of the control group $(\mathrm{P}<0.001)$. The expression level of FGFR2 mRNA in the non-small cell LC tissues was significantly higher than that in the adjacent normal tissues $(\mathrm{P}<0.001)$. The expression level of FGFR2 protein in the non-small cell LC tissues was higher than that in the adjacent normal lung tissues $(\mathrm{P}<0.001)$. The expression levels of FGF2 mRNA and FGFR2 mRNA in cancer tissues were not significantly correlated with age, sex and history of smoking $(\mathrm{P}>0.05)$, but were significantly correlated with lymph node metastasis, tumor differentiation and TNM staging. FGF2 and FGFR2 proteins were highly expressed in cancer tissues of LC patients and lavage fluid of patients with IPF. The expression of FGF2 mRNA and FGFR2 mRNA was correlated with lymph node metastasis and TNM stage. The high expression levels of FGF2 mRNA and FGFR2 mRNA were associated with tumor metastasis and poor prognosis of LC patients.[55] Signal transducer and activator of transcription (STAT) 3 plays a central role in the host response to injury. It is activated rapidly within cells by many cytokines, most notably those in the IL-6 family, leading to pro-proliferative and pro-survival programs that assist the host in regaining homeostasis. With persistent activation, however, chronic inflammation and fibrosis ensue, leading to a number of debilitating diseases.[56] Many STAT3 inhibitors suffer from lack of specificity and have negative impacts on wound healing and immune function.[57] there is a potential risk of toxicity in the use of STAT3 inhibitors associated with inhibiting mitochondrial function, which may be unacceptable, especially in non-cancer indications, such as inflammation and fibrosis.[58] The Warburg effect is the metabolic perturbation in cancer cells meaning that glycolysis is preferred over oxidative phosphorylation, even in the presence of oxygen. This effect has also been observed upon myofibroblast differentiation, a distinct physiopathological step in pulmonary fibrosis.[59] The matricellular protein SPARC (secreted proteome acidic and rich in cysteine) is known to bind collagens and regulate fibrillogenesis. It has been observed that cleavage of SPARC at a specific site, which modulates collagen binding, is a physiological mechanism increased during pathogenesis of lung cancer. Furthermore, inhibition of fibrillar collagen degradation by SPARC may play additional roles in increasing collagen deposition leading to a pro-fibrotic and tumorigenic environment.[60] (Figure 1-2.)

\section{IPF}

It is known that patients suffering from idiopathic pulmonary fibrosis (IPF) have an affected lung parenchyma with scar tissue. This observation can be made with CT of the thorax and biopsies. There are different patterns such as the usual interstitial pneumonia (UIP), however; there are cases where an overlap with non-specific interstitial pneumonia (NSIP) pattern might exist. These patients have an incidence of 25/1000 to develop lung cancer and the most usual type is squamus cell lung cancer.[36] Smoking habit, emphysema have been also correlated with the development of lung cancer and there is a 


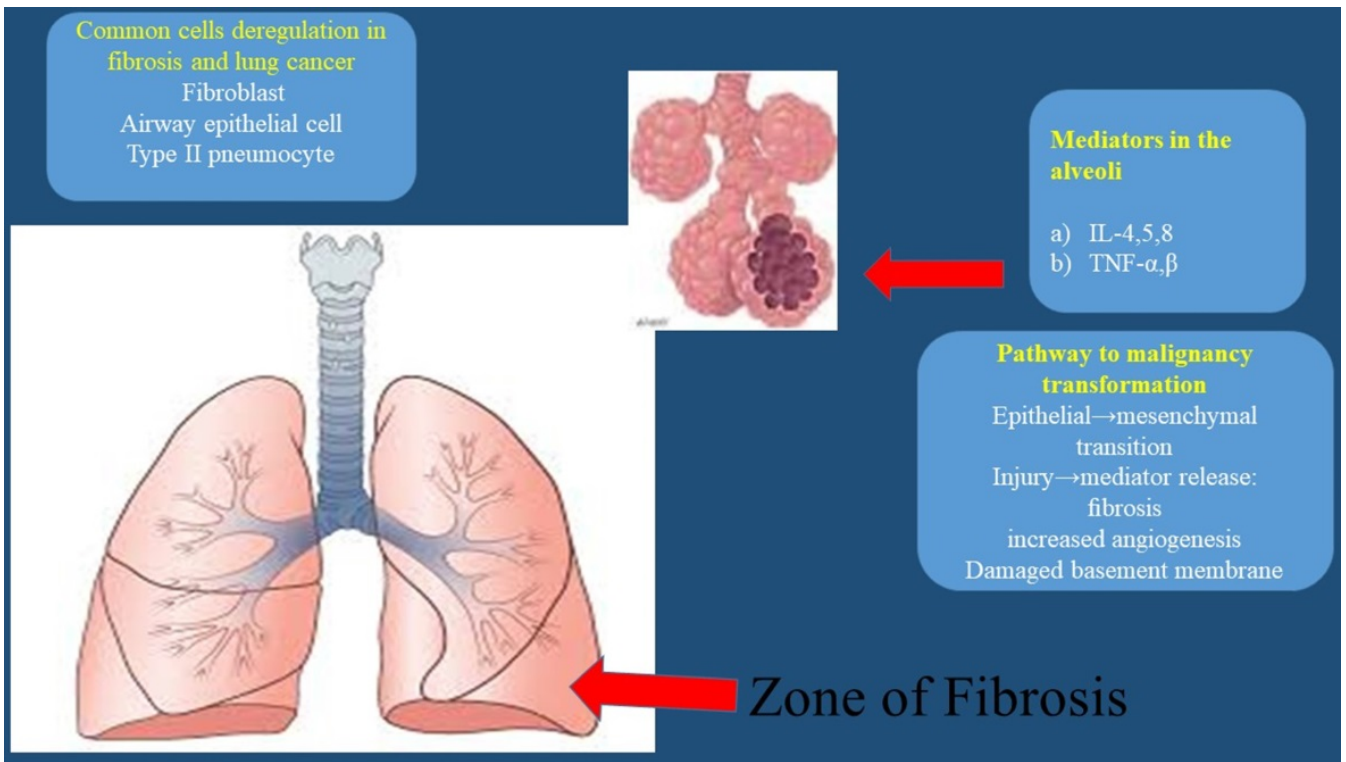

Figure 1. Mechanisms and concept of fibrosis and tumorigenesis; interleukins IL-4,5,8; Tumor Necrosis Factor (TNF) $\alpha, \beta$;

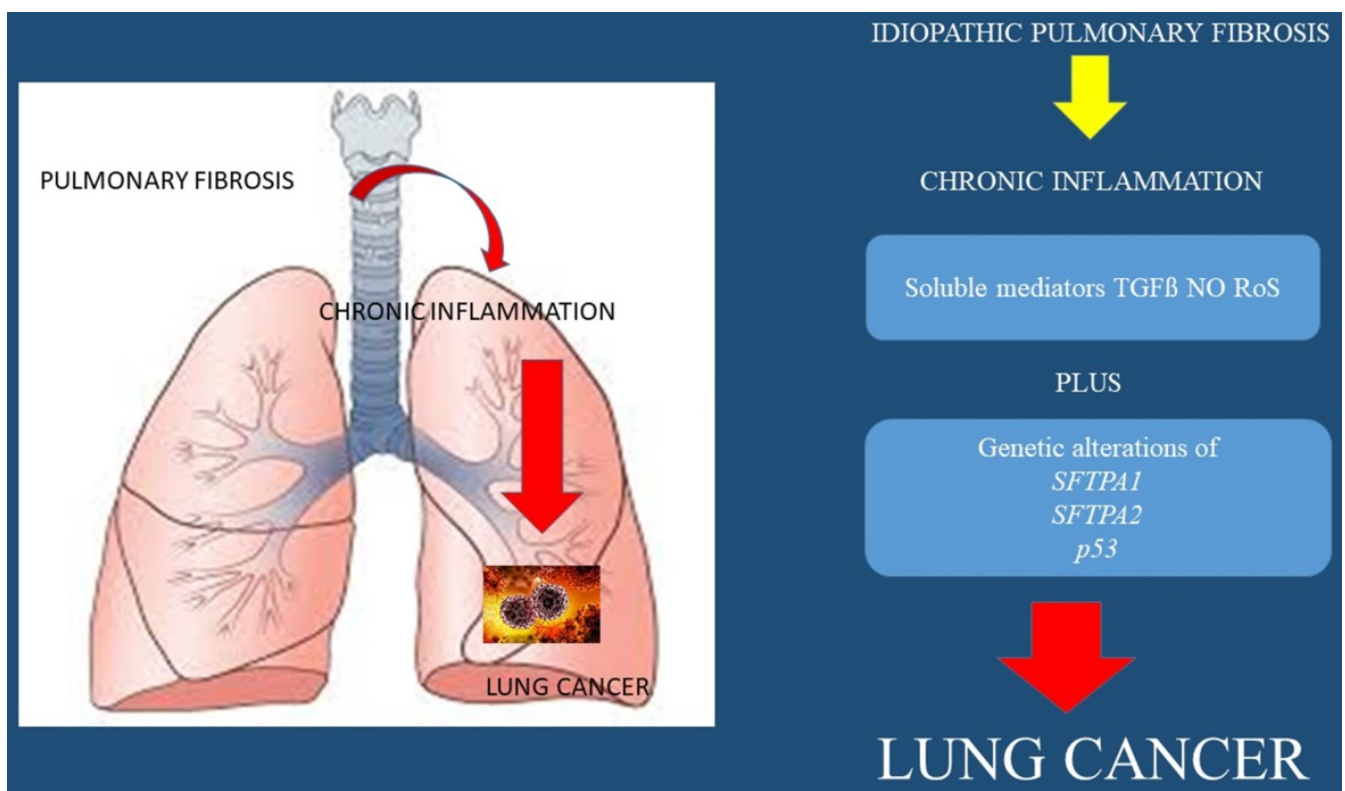

Figure 2. Reactive oxygen species (ROS), Tumor Growth Factor (TGF- $\beta$ ), Nitric Oxide (NO), Surfactant protein 1 (SFTPA1), Surfactant protein 2 (SFTPA2), and tumor protein $\mathrm{p} 53(\mathrm{p} 53)$

high mortality rate one year after the diagnosis of lung cancer in these patients.[36] Moreover; it has observed that the lung cancer lesions develop adjacent to the UIP lesions.[36] Adenocarcinoma has been described between a UIP pattern of a patient that underwent lung transplantation, however; he was not fit for biopsy, this case emphasized the need for non-invasive methods of lung cancer diagnosis.[61] In interstitial pulmonary fibrosis (IPF), chemokine (IL-8) is significantly elevated and has been correlated with the presence of neutrophils in bronchoalveolar lavage fluid (BALF). It has been also observed that during chronic inflammation, abnormal function of inducer or suppressor genes decreases apoptosis of immune cells. This leads to prolongation of inflammatory cell infiltration of the lungs and possibly cancer due to the mechanisms described in the molecular pathology section.[62]

IPF must be distinguished from other ILDs. Like carcinogenesis, IPF physiopathology is primarily based on epithelial damage, repair abnormalities, and epithelial mesenchymal transition, whereas for the other ILD subtypes, inflammation and immunosuppression are paramount features. These last displays a better prognosis that IPF.[59]

It has been observed that surgery for lung cancer with idiopathioc pulmonary fibrosis in the background increases postoperative morbidity and mortality by exacerbating pre-existing IPF, i.e., acute exacerbation of IPF (AEIPF). Additionally, survival 
after lung cancer surgery depends on the presence of IPF.[35]

\section{Connective tissue disease}

Connective tissue disease-associated interstitial lung disease (CTD-ILD) has been found to be associated with lung cancer.[63] Connective tissue disease (CTD) represents a group of immunologicallymediated inflammatory disorders that affect a variety of organs. CTD includes rheumatoid arthritis (RA), Sjögren's syndrome (SS), systemic sclerosis (SSc), systemic lupus erythematosus (SLE), polymyositis/ dermatomyositis (PM/DM) and mixed connective tissue disease. The relationship between CTD and LC has not been fully investigated. However; for rheumatoid arthritis[64, 65], systemic sclerosis[66, 67] and dermatomyositis/polymyositis[68,69] there are publications which connect one disease with the other.

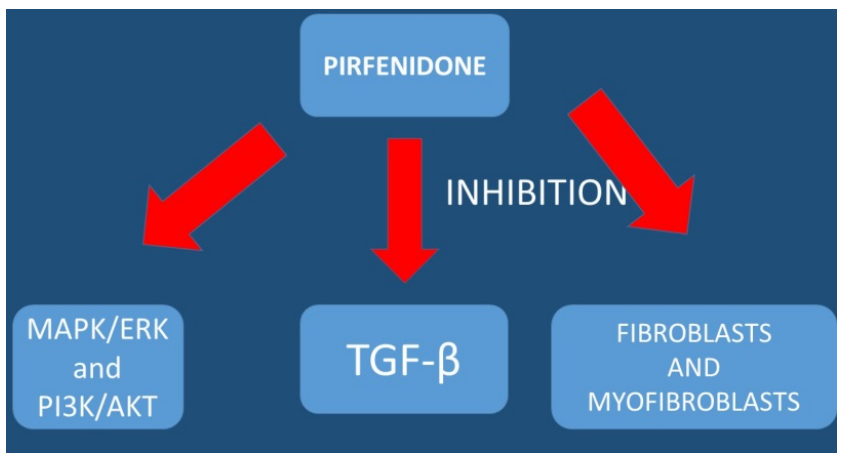

Figure 3. TGF- $\beta$; tumor growth factor-beta, MAPK/ERK; Ras-Raf-MEK-ERK pathway) is a chain of proteins in the cell that communicates a signal from a receptor on the surface of the cell to the DNA in the nucleus of the cell, PI3K/AKT; PI3K/AKT/mTOR pathway is an intracellular signaling pathway important in regulating the cell cycle.

\section{Outlook}

The pathophysiology of interstitial lung diseases, particularly IPF, resembles that of cancer development. It includes epithelial cell anomalies ranging from metaplasia to carcinomatous transformation, gene alterations, soluble mediator release, cellular bioenergetics, and aging with telomere attrition and aberrant recapitulation of developmental pathways.[59] Interstitial pneumonia (IP) is a known risk factor for lung cancer. It has been observed that the prevalence of IP in patients with lung cancer is approximately 4-8\%.[70] Previous large-scale retrospective studies have included patients treated with steroids, ulinastatin, sivelestat sodium, macrolides, or other agents for the prevention of postoperative adverse events, although none of these agents has proven to be effective.[70] It is known that chronic inflammation induced by emphysema or fibrosis can result in epithelial cell injury, propagation of DNA errors and high cell turnover rates, thereby promoting carcinogenesis.[71] It has been observed that low DLCO may facilitate oxygen deprivation and increase the expression of hypoxia-inducible factors (HIFs). Hypoxia-inducible factor expression has been associated with tumor metastasis in lung cancer.[72] Hypoxia is also known to have extensive crosstalk with signaling pathways linked to inflammation.[73] There are drugs such as; pirfenidone that inhibit mesothelioma cell proliferation and migration via inhibition of extracellular signal-regulated kinases (ERK) and serine/threonine-specific protein kinase (AKT) and regulates mesothelioma tumor microenvironment in vivo.[74] Pirfenidone alone does not act against cancer cells, but it downregulates the expression of extracellular matrix associated genes and also decreases significantly Transwell migration/invasion and 3D collagen invasion.[75]

The addition of cisplatin in combination with pirfenidone provide a combined therapeutic effect as pirfenidone enhances the effect of cisplatin in these patients by modifying the tumor microenvironment and increase the drug penetration. [74] It is known that pulmonary fibrosis and lung cancer share the common pathogenesis, epigenetic and genetic changes, abnormal expression of microRNAs, activation of specific signaling pathways and altered response to regulatory signals which can be attributed to the causes of both fibrotic change and carcinogenesis.[76] Moreover; hypoxia-inducible factors expression can contribute towards the better understanding of the underlying molecular mechanism between low DLCO values and high tumor aggressiveness and metastasis.[77] Five Japanese series compared EGFR gene mutation frequencies in non-small cell lung cancer patients with and without interstitial lung disease. Epidermal growth factor receptor mutations were detected in $0-5.8 \%$ of tumors in interstitial lung disease patients versus $24.3-47 \%$ in those without.[59] A multivariate analysis revealed EGFR mutations to be independently associated with absent ILD.[78] EGFR mutations are very rare in lung cancer patients with IPF and maybe tkis could be a contraindicated for these patients since they might induce pneumonitis and further worsen their respiratory capacity. However; since the number of these patients is very low, further studies should be made to clarify this issue. Prevalence of lung cancer in patients with interstitial lung disease is higher than in those with chronic obstructive pulmonary disease.[79] In conclusion low lung diffusion capacity (DLCO), repeated exacerbations, underlying CTD, insufficient antiviral prophylaxis, radiological pattern and 
treatment are the most important factors affecting the newly diagnosed patient with lung cancer and connective tissue underlying disease. Patients with CTD and IPF are diagnosed more frequently in early stages due to the continuous and frequent screening medical practice which is not the same with COPD patients and smoking history.[80] Tumors are more frequently observed in the lower lobes and lung periphery, which usually adjoined the fibrous area.[80] Moreover; patients with IPF-LC were more likely to have sublobar resection and shorter anesthesia time due to the early stage when diagnosed.[80] It has been observed that mechanical ventilator care and deaths were more common in idiopathic pulmonary fibrosis-lung cancer patients compared to lung cancer only patients.[80] However; biopsy and treatment are difficult to perform in several of them.[80] Survival time has been found to be significantly shorter in patients with IPFLC when compared to lung cancer.[80] It has been observed that chemotherapy for advanced-disease raises the issue of feasibility and acute events-interstitial lung disease risk, with the exact role of interstitial lung disease and lung cancer therapies be better administered.[59] On the other hand factors that might induce lung cancer can be summarized to: male sex[79], older age $\geq 60[79]$, heavy smokers, higher number of cigarettes, have rheumatoid arthritis[64, 65], systemic sclerosis[66, 67], dermatomyositis/ polymyositis[68, 69], have a usual interstitial pneumonia (UIP) pattern and presence of emphysema on HRCT scan, lower predicted diffusing capacity of the lung carbon monoxide (DLco)\%, and not be receiving immunosuppressive therapy. Women were at a higher risk of developing cancer than men in those with systemic lupus erythematosus.[81] We still do not have enough data regarding immunotherapy for lung cancer patients and idiopathic pulmonary fibrosis. These patients are very rare to find even in clinical trials. Moreover; we now that immunotherapy might induce pneumonitis in some patients, either pembrolizumab or nivolumab.[82] Therefore maybe this type of therapy should be avoided. However; since these drugs are certified for other lung cancer patients maybe these agents could be administered with a close follow up with spirometry, DLCO and CT of the thorax for an adverse reaction. On the other hand again tyrosine kinase inhibitors can cause pneumonitis, however; they have been administered previously in these patients as they have been longer in the market than immunotherapy. [83] The combination of the drug pirfenidone with chemotherapy or even tyrosine kinase inhibitors could be an option, since we have data that pirfenidone might work synergistically with another therapeutic agent of lung cancer (chemotherapy and tkis).[74]

Electromagnetic navigation is another method of diagnosis for small central and peripheral lesions.[84] Medical thoracoscopy can be used in case of malignancy of the pleura.[85] This method can be performed in some cases with local sedation, however; for some patients general anesthesia has to be used. The methods that we currently have for lung cancer diagnosis are minimal invasive and are suitable for all candidates. The appropriate method of diagnosis will be chosen based on the respiratory capacity of a patient, site of the lesion and performance status. Pneumothorax is a situation that can be handled with minimal aspiration systems and therefore it should not be a contraindication even with patients with low oxygen saturation levels. Again low oxygen saturation levels on its own as a factor it is not a contraindication in order to perform an endoscopy.[86]

Patients with lung cancer and idiopathic pulmonary fibrosis are rarely diagnosed with epidermal growth factor expression, anaplastic lymphoma kinase expression, BRAF or ROS1 expression. Since IPF is considered a systematic disease different pathways are deregulated. We have this information from patients who underwent double lung transplantation and pulmonary fibrosis occurred again.[87] There are possibly antibodies that attack the lung parenchyma. Patients with EGFR positive expression are usually non-smokers and it is known that they have a genetic predisposition.[88] The same with ALK positive expression patients.[89]

\section{Note}

We should mention that several studies from which we obtained information for this work, the patients in some of them were not diagnosed with IPF or CTD with ATS/ERS/JRS/ALAT.

\section{Competing Interests}

The authors have declared that no competing interest exists.

\section{References}

1. Haidong $\mathrm{H}$, Yunye N, Wei Z, Zarogoulidis P, Hohenforst-Schmidt W, Man YG, et al. Multiple guided technologies based on radial probe endobronchial ultrasound for the diagnosis of solitary peripheral pulmonary lesions: a single-center study. Journal of Cancer. 2017; 8: 3514-21. doi:10.7150/jca.20035.

2. Zaric B, Stojsic V, Carapic V, Kovacevic T, Stojanovic G, Panjkovic M, et al. Radial Endobronchial Ultrasound (EBUS) Guided Suction Catheter-Biopsy in Histological Diagnosis of Peripheral Pulmonary Lesions. Journal of Cancer. 2016; 7: 7-13. doi:10.7150/jca.13081.

3. Zarogoulidis P, Huang $\mathrm{H}$, Bai $\mathrm{C}$, Kosmidis C, Trakada G, Veletza L, et al. Endobronchial ultrasound convex probe for lymphoma, sarcoidosis, lung cancer and other thoracic entities. A case series. Respiratory medicine case reports. 2017; 22: 187-96. doi:10.1016/j.rmcr.2017.08.016

4. Domvri K, Darwiche K, Zarogoulidis P, Zarogoulidis K. Following the crumbs: from tissue samples, to pharmacogenomics, to NSCLC therapy. Translational lung cancer research. 2013; 2: 256-8. doi:10.3978/j.issn.2218-6751.2012.12.06. 
5. Domvri K, Zarogoulidis P, Darwiche K, Browning RF, Li Q, Turner JF, et al. Molecular Targeted Drugs and Biomarkers in NSCLC, the Evolving Role of Individualized Therapy. Journal of Cancer. 2013; 4: 736-54. doi:10.7150/jca.7734.

6. Kimura H, Ohira T, Uchida O, Matsubayashi J, Shimizu S, Nagao T, et al. Analytical performance of the cobas EGFR mutation assay for Japanese non-small-cell lung cancer. Lung cancer. 2014; 83: 329-33. doi:10.1016/j.lungcan.2013.12.012

7. Thress KS, Brant R, Carr TH, Dearden S, Jenkins S, Brown H, et al. EGFR mutation detection in ctDNA from NSCLC patient plasma: A cross-platform comparison of leading technologies to support the clinical development of AZD9291. Lung cancer. 2015; 90: 509-15. doi:10.1016/j.lungcan.2015.10.004.

8. Angulo B, Lopez-Rios F, Gonzalez D. A new generation of companion diagnostics: cobas BRAF, KRAS and EGFR mutation detection tests. Expert review of molecular diagnostics. 2014; 14: 517-24. doi:10.1586/14737159.2014.910120.

9. Li C, Jia R, Liu H, Zhang B, Wang C. EGFR T790M detection and osimertinib treatment response evaluation by liquid biopsy in lung adenocarcinoma patients with acquired resistance to first generation EGFR tyrosine kinase inhibitors. Diagnostic pathology. 2018; 13: 49. doi:10.1186/s13000-018-0728-6.

10. Chougule A, Basak S. Epidermal growth factor receptor T790M testing in progressed lung cancer: A review of sensitive methods for analysis of tissue and liquid biopsy samples. Indian journal of cancer. 2017; 54: S45-S54. doi:10.4103/ijc.IJC 540_17.

11. Zarogoulidis P, Gaga M, Huang H, Darwiche K, Rapti A, Hohenforst-Schmidt W. Tissue is the issue and tissue competition. Re-biopsy for mutation T790: where and why? Clinical and translational medicine. 2017; 6: 6 . doi:10.1186/s40169-017-0135-8.

12. Bertolaccini L, Pardolesi A, Brandolini J, Solli P. Uniportal video-assisted thoracic surgery for pneumothorax and blebs/bullae. Journal of visualized surgery. 2017; 3: 107. doi:10.21037/jovs.2017.07.04.

13. Suda K, Murakami I, Yu H, Kim J, Ellison K, Rivard CJ, et al. Heterogeneity in Immune Marker Expression after Acquisition of Resistance to EGFR Kinase Inhibitors: Analysis of a Case with Small Cell Lung Cancer Transformation. Journal of thoracic oncology : official publication of the International Association for the Study of Lung Cancer. 2017; 12: 1015-20. doi:10.1016/j.jtho.2017.02.002

14. Zarogoulidis P, Yarmus L, Zarogoulidis K. New insights for IL-6 targeted therapy as an adjuvant treatment for non-small-cell lung cancer. Therapeutic delivery. 2013; 4: 1221-3. doi:10.4155/tde.13.95

15. Zarogoulidis P, Katsikogianni F, Tsiouda T, Sakkas A, Katsikogiannis N, Zarogoulidis K. Interleukin-8 and interleukin-17 for cancer. Cancer investigation. 2014; 32: 197-205. doi:10.3109/07357907.2014.898156.

16. Zarogoulidis P, Lampaki S, Yarmus L, Kioumis I, Pitsiou G, Katsikogiannis N, et al. Interleukin-7 and interleukin-15 for cancer. Journal of Cancer. 2014; 5: 765-73. doi:10.7150/jca.10471.

17. Suh $\mathrm{CH}$, Park HS, Kim KW, Pyo J, Hatabu H, Nishino M. Pneumonitis in advanced non-small-cell lung cancer patients treated with EGFR tyrosine kinase inhibitor: Meta-analysis of 153 cohorts with 15,713 patients: Meta-analysis of incidence and risk factors of EGFR-TKI pneumonitis in NSCLC. Lung cancer. 2018; 123: 60-9. doi:10.1016/j.lungcan.2018.06.032.

18. Babu Koyyala VP, Batra U, Jain P, Sharma M, Goyal P, Medisetty P, et al. Frequency of T790M mutations after progression on epidermal growth factor receptor tyrosine kinase inhibitor in metastatic non-small cell lung cancer in Indian patients: real-time data from tertiary cancer hospital. Lung India : official organ of Indian Chest Society. 2018; 35: 390-4. doi:10.4103/lungindia.lungindia_451_17.

19. Ishioka K, Sasada S, Ohgino K, Sakai T, Takahashi S, Xu C, et al. Detection of EGFR T790M in a Large Amount of Malignant Ascites Cellblock. Gan to kagaku ryoho Cancer \& chemotherapy. 2018; 45: 1185-7.

20. Nakao M, Suzuki Y, Arakawa S, Sakai Y, Fujita K, Ishikawa M, et al. [Osimertinib for an Elderly Patient with Adenocarcinoma of the Lung Harboring EGFR T790M Mutation Diagnosed Using a Pleural Fluid Cell Block]. Gan to kagaku ryoho Cancer \& chemotherapy. 2018; 45: 1177-80.

21. Passiglia F, Raez LE, Rolfo C. Moving osimertinib to first-line: the right "strategy" in the chessboard of epidermal growth factor receptor-mutated non-small cell lung cancer? Journal of thoracic disease. 2018; 10: S1076-S80. doi:10.21037/jtd.2018.03.92

22. Soria JC, Ohe Y, Vansteenkiste J, Reungwetwattana T, Chewaskulyong B, Lee $\mathrm{KH}$, et al. Osimertinib in Untreated EGFR-Mutated Advanced Non-Small-Cell Lung Cancer. The New England journal of medicine. 2018; 378: 113-25. doi:10.1056/NEJMoa1713137.

23. Solomon BJ, Mok T, Kim DW, Wu YL, Nakagawa K, Mekhail T, et al. First-line crizotinib versus chemotherapy in ALK-positive lung cancer. The New England journal of medicine. 2014; 371: 2167-77. doi:10.1056/NEJMoa1408440.

24. Duffy MJ, O'Byrne K. Tissue and Blood Biomarkers in Lung Cancer: A Review. Advances in clinical chemistry. 2018; 86: 1-21. doi:10.1016/bs.acc.2018.05.001.

25. Gainor JF, Tan DS, De Pas T, Solomon BJ, Ahmad A, Lazzari C, et al. Progression-Free and Overall Survival in ALK-Positive NSCLC Patients Treated with Sequential Crizotinib and Ceritinib. Clinical cancer research : an official journal of the American Association for Cancer Research. 2015; 21: 2745-52. doi:10.1158/1078-0432.CCR-14-3009.

26. Vavala T, Novello S. Alectinib in the treatment of ALK-positive non-small cell lung cancer: an update on its properties, efficacy, safety and place in therapy.
Therapeutic advances in medical oncology. 2018; 10: 1758835918789364. doi:10.1177/1758835918789364

27. Zhang S, Anjum R, Squillace R, Nadworny S, Zhou T, Keats J, et al. The Potent ALK Inhibitor Brigatinib (AP26113) Overcomes Mechanisms of Resistance to First- and Second-Generation ALK Inhibitors in Preclinical Models. Clinical cancer research : an official journal of the American Association for Cancer Research. 2016; 22: 5527-38. doi:10.1158/1078-0432.CCR-16-0569.

28. Shaw AT, Ou SH, Bang YJ, Camidge DR, Solomon BJ, Salgia R, et al. Crizotinib in ROS1-rearranged non-small-cell lung cancer. The New England journal of medicine. 2014; 371: 1963-71. doi:10.1056/NEJMoa1406766.

29. Lim SM, Kim HR, Lee JS, Lee KH, Lee YG, Min YJ, et al. Open-Label, Multicenter, Phase II Study of Ceritinib in Patients With Non-Small-Cell Lung Cancer Harboring ROS1 Rearrangement. Journal of clinical oncology : official journal of the American Society of Clinical Oncology. 2017; 35: 2613-8. doi:10.1200/JCO.2016.71.3701.

30. Weart TC, Miller KD, Simone CB, 2nd. Spotlight on dabrafenib/trametinib in the treatment of non-small-cell lung cancer: place in therapy. Cancer management and research. 2018; 10: 647-52. doi:10.2147/CMAR.S142269.

31. Dinges HC, Capper D, Ritz O, Bruderlein S, Marienfeld R, von Deimling A, et al. Validation of a Manual Protocol for BRAF V600E Mutation-specific Immunohistochemistry. Applied immunohistochemistry \& molecular morphology : AIMM. 2015; 23: 382-8. doi:10.1097/PAI.0000000000000092.

32. Firestone AJ, Settleman J. A three-drug combination to treat BRAF-mutant cancers. Nature medicine. 2017; 23: 913-4. doi:10.1038/nm.4382.

33. Reckamp KL. Advances in immunotherapy for non-small cell lung cancer. Clinical advances in hematology \& oncology : H\&O. 2015; 13: 847-53.

34. Spigel DR, Socinski MA. Rationale for chemotherapy, immunotherapy, and checkpoint blockade in SCLC: beyond traditional treatment approaches. Journal of thoracic oncology : official publication of the International Association for the Study of Lung Cancer. 2013; 8: 587-98. doi:10.1097/JTO.0b013e318286cf88.

35. Goto T. Measuring Surgery Outcomes of Lung Cancer Patients with Concomitant Pulmonary Fibrosis: A Review of the Literature. Cancers. 2018; 10. doi:10.3390/cancers10070223.

36. Kato E, Takayanagi N, Takaku Y, Kagiyama N, Kanauchi T, Ishiguro T, et al. Incidence and predictive factors of lung cancer in patients with idiopathic pulmonary fibrosis. ERJ open research. 2018; 4: 00111-2016. doi:10.1183/23120541.00111-2016.

37. Vancheri C. Idiopathic pulmonary fibrosis and cancer: do they really look similar? BMC medicine. 2015; 13: 220. doi:10.1186/s12916-015-0478-1.

38. Vancheri C, Failla M, Crimi N, Raghu G. Idiopathic pulmonary fibrosis: a disease with similarities and links to cancer biology. The European respiratory journal. 2010; 35: 496-504. doi:10.1183/09031936.00077309.

39. Jones MG, Andriotis OG, Roberts JJ, Lunn K, Tear VJ, Cao L, et al. Nanoscale dysregulation of collagen structure-function disrupts mechano-homeostasis and mediates pulmonary fibrosis. eLife. 2018; 7: e36354. doi:10.7554/eLife.36354.

40. Porrello A, Leslie PL, Harrison EB, Gorentla BK, Kattula S, Ghosh SK, et al. Factor XIIIA-expressing inflammatory monocytes promote lung squamous cancer through fibrin cross-linking. Nature communications. 2018; 9: 1988. doi:10.1038/s41467-018-04355-w.

41. Wang Z, Li W, Guo Q, Wang Y, Ma L, Zhang X. Insulin-Like Growth Factor-1 Signaling in Lung Development and Inflammatory Lung Diseases. BioMed research international. 2018; 2018: 6057589. doi:10.1155/2018/6057589.

42. Allen JT, Bloor CA, Kedia RK, Knight RA, Spiteri MA. Expression of growth hormone-releasing factor, growth hormone, insulin-like growth factor-1 and its binding proteins in human lung. Neuropeptides. 2000; 34: 98-107. doi:10.1054/npep.2000.0802.

43. Stiles AD, D'Ercole AJ. The insulin-like growth factors and the lung. American journal of respiratory cell and molecular biology. 1990; 3: 93-100. doi:10.1165/ajrcmb/3.2.93.

44. Kim WY, Jin $\mathrm{O}$ Oh SH, Kim ES, Yang YJ, Lee DH, et al. Elevated epithelial insulin-like growth factor expression is a risk factor for lung cancer $\begin{array}{llll}\text { development. Cancer } & \text { research. 2009; 69: 7439-48. }\end{array}$ doi:10.1158/0008-5472.CAN-08-3792.

45. Yoo SH, Ryu JA, Kim SR, Oh SY, Jung GS, Lee DJ, et al. Afatinib-Induced Acute Fatal Pneumonitis in Metastatic Lung Adenocarcinoma. Korean journal of family medicine. 2016; 37: 351-5. doi:10.4082/ kifm.2016.37.6.351.

46. Nurwidya F, Andarini S, Takahashi F, Syahruddin E, Takahashi K. Implications of Insulin-like Growth Factor 1 Receptor Activation in Lung Cancer. The Malaysian journal of medical sciences : MJMS. 2016; 23: 9-21.

47. Yao L, Conforti F, Hill C, Bell J, Drawater L, Li J, et al. Paracrine signalling during ZEB1-mediated epithelial-mesenchymal transition augments local myofibroblast differentiation in lung fibrosis. Cell death and differentiation. 2018; [Epub ahead of print]. doi:10.1038/s41418-018-0175-7.

48. van Moorsel CHM. Trade-offs in aging lung diseases: a review on shared but opposite genetic risk variants in idiopathic pulmonary fibrosis, lung cancer and chronic obstructive pulmonary disease. Current opinion in pulmonary medicine. 2018; 24: 309-17. doi:10.1097/MCP.0000000000000476.

49. Snetselaar R, van Oosterhout MFM, Grutters JC, van Moorsel CHM. Telomerase Reverse Transcriptase Polymorphism rs2736100: A Balancing Act between Cancer and Non-Cancer Disease, a Meta-Analysis. Frontiers in medicine. 2018; 5: 41. doi:10.3389/fmed. 2018.00041.

50. Katoh M. Multilayered prevention and treatment of chronic inflammation, organ fibrosis and cancer associated with canonical WNT/betacatenin 
signaling activation (Review). International journal of molecular medicine. 2018; 42: 713-25. doi:10.3892/ijmm.2018.3689.

51. Lawrence J, Nho R. The Role of the Mammalian Target of Rapamycin (mTOR) in Pulmonary Fibrosis. International journal of molecular sciences. 2018; 19. doi:10.3390/ijms19030778.

52. Kafaja S, Valera I, Divekar AA, Saggar R, Abtin F, Furst DE, et al. pDCs in lung and skin fibrosis in a bleomycin-induced model and patients with systemic sclerosis. JCI insight. 2018; 3. doi:10.1172/jci.insight.98380.

53. Miyazono K, Katsuno Y, Koinuma D, Ehata S, Morikawa M. Intracellular and extracellular TGF-beta signaling in cancer: some recent topics. Frontiers of medicine. 2018; 12: 387-411. doi:10.1007/s11684-018-0646-8.

54. Bibaki E, Tsitoura E, Vasarmidi E, Margaritopoulos G, Trachalaki A, Koutoulaki C, et al. miR-185 and miR-29a are similarly expressed in the bronchoalveolar lavage cells in IPF and lung cancer but common targets DNMT1 and COL1A1 show disease specific patterns. Molecular medicine reports. 2018; 17: 7105-12. doi:10.3892/mmr.2018.8778.

55. Li L, Zhang S, Wei L, Wang Z, Ma W, Liu F, et al. FGF2 and FGFR2 in patients with idiopathic pulmonary fibrosis and lung cancer. Oncology letters. 2018; 16 : 2490-4. doi:10.3892/ol.2018.8903.

56. Kasembeli MM, Bharadwaj U, Robinson P, Tweardy DJ. Contribution of STAT3 to Inflammatory and Fibrotic Diseases and Prospects for its Targeting for Treatment. International journal of molecular sciences. 2018; 19. doi:10.3390/ijms19082299.

57. Bharadwaj U, Eckols TK, Xu X, Kasembeli MM, Chen Y, Adachi M, et al. Small-molecule inhibition of STAT3 in radioresistant head and neck squamous cell carcinoma. Oncotarget. 2016; 7: 26307-30. doi:10.18632/oncotarget.8368

58. Wegrzyn J, Potla R, Chwae YJ, Sepuri NB, Zhang Q, Koeck T, et al. Function of mitochondrial Stat3 in cellular respiration. Science. 2009; 323: 793-7. doi:10.1126/science.1164551.

59. Naccache JM, Gibiot Q, Monnet I, Antoine M, Wislez M, Chouaid C, et al. Lung cancer and interstitial lung disease: a literature review. Journal of thoracic disease. 2018; 10: 3829-44. doi:10.21037/jtd.2018.05.75.

60. Kehlet SN, Manon-Jensen T, Sun S, Brix S, Leeming DJ, Karsdal MA, et al. A fragment of SPARC reflecting increased collagen affinity shows pathological relevance in lung cancer - implications of a new collagen chaperone function of SPARC. Cancer biology \& therapy. 2018; 19: 904-12. doi:10.1080/15384047.2018.1480887.

61. Patil PD, Sultan S, Hahn MF, Roy SB, Ross MD, Abdelrazek H, et al. Incidental extensive adenocarcinoma in lungs explanted from a transplant recipient with an idiopathic pulmonary fibrosis flare-up: A clinical dilemma. Respiratory medicine case reports. 2018; 25: 45-8. doi:10.1016/j.rmcr.2018.06.005.

62. Moldoveanu B, Otmishi P, Jani P, Walker J, Sarmiento X, Guardiola J, et al. Inflammatory mechanisms in the lung. Journal of inflammation research. 2009; 2: $1-11$.

63. Watanabe S, Saeki K, Waseda Y, Murata A, Takato H, Ichikawa Y, et al. Lung cancer in connective tissue disease-associated interstitial lung disease: clinical features and impact on outcomes. Journal of thoracic disease. 2018; 10: 799-807. doi:10.21037/jtd.2017.12.134

64. Yamada T, Nakajima A, Inoue E, Tanaka E, Taniguchi A, Momohara S, et al. Incidence of malignancy in Japanese patients with rheumatoid arthritis. Rheumatology international. 2011; 31: 1487-92. doi:10.1007/s00296-010-1524-0.

65. Parikh-Patel A, White RH, Allen M, Cress R. Risk of cancer among rheumatoid arthritis patients in California. Cancer causes \& control : CCC. 2009; 20: 1001-10. doi:10.1007/s10552-009-9298-y.

66. Kang KY, Yim HW, Kim IJ, Yoon JU, Ju JH, Kim HY, et al. Incidence of cancer among patients with systemic sclerosis in Korea: results from a single centre. Scandinavian journal of rheumatology. 2009; 38: 299-303. doi:10.1080/03009740802642062.

67. Hill CL, Nguyen AM, Roder D, Roberts-Thomson P. Risk of cancer in patients with scleroderma: a population based cohort study. Annals of the rheumatic diseases. 2003; 62: 728-31.

68. Huang YL, Chen YJ, Lin MW, Wu CY, Liu PC, Chen TJ, et al. Malignancies associated with dermatomyositis and polymyositis in Taiwan: a nationwide population-based study. The British journal of dermatology. 2009; 161: 854-60. doi:10.1111/j.1365-2133.2009.09274.x.

69. Hill CL, Zhang Y, Sigurgeirsson B, Pukkala E, Mellemkjaer L, Airio A, et al. Frequency of specific cancer types in dermatomyositis and polymyositis: a population-based study. Lancet. 2001; 357: 96-100. doi:10.1016/S0140-6736(00)03540-6.

70. Saito Y, Kawai Y, Takahashi N, Ikeya T, Murai K, Kawabata Y, et al. Survival after surgery for pathologic stage IA non-small cell lung cancer associated with idiopathic pulmonary fibrosis. The Annals of thoracic surgery. 2011; 92: 1812-7. doi:10.1016/j.athoracsur.2011.06.055.

71. Malkinson AM. Role of inflammation in mouse lung tumorigenesis: a review. Experimental lung research. 2005; 31: 57-82.

72. Ren W, Mi D, Yang K, Cao N, Tian J, Li Z, et al. The expression of hypoxia-inducible factor-1alpha and its clinical significance in lung cancer: a systematic review and meta-analysis. Swiss medical weekly. 2013; 143: w13855. doi:10.4414/smw.2013.13855.

73. Eltzschig HK, Carmeliet P. Hypoxia and inflammation. The New England journal of medicine. 2011; 364: 656-65. doi:10.1056/NEJMra0910283.

74. Li C, Rezov V, Joensuu E, Vartiainen V, Ronty M, Yin M, et al. Pirfenidone decreases mesothelioma cell proliferation and migration via inhibition of ERK and AKT and regulates mesothelioma tumor microenvironment in vivo. Scientific reports. 2018; 8: 10070. doi:10.1038/s41598-018-28297-x.
75. Tanino $Y$. Does pirfenidone have anticancer effects in patients with idiopathic pulmonary fibrosis? Respiratory investigation. 2018; 56: 95-6. doi:10.1016/j.resinv.2017.12.001.

76. Vancheri C. Common pathways in idiopathic pulmonary fibrosis and cancer. European respiratory review : an official journal of the European Respiratory Society. 2013; 22: 265-72. doi:10.1183/09059180.00003613.

77. Nakazawa S, Shimizu K, Mogi A, Kuwano H. Low diffusing capacity, emphysema, or pulmonary fibrosis: who is truly pulling the lung cancer strings? Journal of thoracic disease. 2018; 10: 600-2. doi:10.21037/jtd.2017.12.145.

78. Fujimoto D, Tomii $\mathrm{K}$, Otoshi $\mathrm{T}$, Kawamura $\mathrm{T}$, Tamai $\mathrm{K}$, Takeshita J, et al Preexisting interstitial lung disease is inversely correlated to tumor epidermal growth factor receptor mutation in patients with lung adenocarcinoma. Lung cancer. 2013; 80: 159-64. doi:10.1016/j.lungcan.2013.01.017.

79. Jung HI, Park JS, Lee MY, Park B, Kim HJ, Park SH, et al. Prevalence of lung cancer in patients with interstitial lung disease is higher than in those with chronic obstructive pulmonary disease. Medicine. 2018; 97: e0071. doi:10.1097/MD.0000000000010071.

80. Lee T, Park JY, Lee HY, Cho YJ, Yoon HI, Lee JH, et al. Lung cancer in patients with idiopathic pulmonary fibrosis: clinical characteristics and impact on survival. Respiratory medicine. 2014; 108: 1549-55. doi:10.1016/j.rmed.2014.07.020.

81. Bernatsky S, Ramsey-Goldman R, Clarke AE. Malignancy in systemic lupus erythematosus: what have we learned? Best practice \& research Clinical rheumatology. 2009; 23: 539-47. doi:10.1016/j.berh.2008.12.007.

82. Nishino M, Sholl LM, Hodi FS, Hatabu H, Ramaiya NH. Anti-PD-1-Related Pneumonitis during Cancer Immunotherapy. The New England journal of medicine. 2015; 373: 288-90. doi:10.1056/NEJMc1505197.

83. Kuo LC, Lin PC, Wang KF, Yuan MK, Chang SC. Successful treatment of gefitinib-induced acute interstitial pneumonitis with high-dose corticosteroid: a case report and literature review. Medical oncology. 2011; 28: 79-82. doi:10.1007/s12032-010-9424-4

84. Hohenforst-Schmidt W, Zarogoulidis P, Vogl T, Turner JF, Browning R, Linsmeier B, et al. Cone Beam Computertomography (CBCT) in Interventional Chest Medicine - High Feasibility for Endobronchial Realtime Navigation. Journal of Cancer. 2014; 5: 231-41. doi:10.7150/jca.8834.

85. Paliouras D, Barbetakis N, Lazaridis G, Baka S, Mpoukovinas I, Karavasilis V, et al. Video-assisted thoracic surgery and pneumothorax. Journal of thoracic disease. 2015; 7: S56-61. doi:10.3978/j.issn.2072-1439.2015.01.35.

86. Hohenforst-Schmidt W, Zarogoulidis P, Huang H, Man YG, Laskou S, Koulouris C, et al. A New and Safe Mode of Ventilation for Interventional Pulmonary Medicine: The Ease of Nasal Superimposed High Frequency Jet Ventilation. Journal of Cancer. 2018; 9: 816-33. doi:10.7150/jca.23737.

87. Kistler KD, Nalysnyk L, Rotella P, Esser D. Lung transplantation in idiopathic pulmonary fibrosis: a systematic review of the literature. BMC pulmonary medicine. 2014; 14: 139. doi:10.1186/1471-2466-14-139.

88. Zhang YL, Yuan JQ, Wang KF, Fu XH, Han XR, Threapleton D, et al. The prevalence of EGFR mutation in patients with non-small cell lung cancer: a systematic review and meta-analysis. Oncotarget. 2016; 7: 78985-93. doi:10.18632/oncotarget.12587.

89. Hensing T, Chawla A, Batra R, Salgia R. A personalized treatment for lung cancer: molecular pathways, targeted therapies, and genomic characterization. Advances in experimental medicine and biology. 2014; 799: 85-117. doi:10.1007/978-1-4614-8778-4_5. 